(c) The children at these clinics should be examined by the tuberculosis officer, and each hospital would have to consider the advisability of affiliating the tuberculosis officer in some suitable manner to the medical staff.

(d) The ultimate responsibility for the work at the clinic, when set up at a hospital, should rest with the paediatrician, on whose opinion the tuberculosis officer should be able to call in any doubtful or difficult case. Where clinics are held at hospitals with medical schools, the medical students should attend for instruction. It may be mentioned that such an arrangement bears comparison with the L.C.C. Rheumatism Clinics for children maintained before the war at some of the London hospitals.

(e) Short courses of instruction in childhood tuberculosis should be given by paediatricians and should be available to tuberculosis officers as well as to general practitioners. Arrangements for these courses might possibly be made through the British Post-Graduate Medical School.

6. The general practitioner: In the attack against respiratory tuberculosis in children the part to be played by the general practitioner cannot be overlooked. In many districts, especially country districts, the responsibility for finding and examining child contacts will be his. It should be the duty of the county tuberculosis authority to place within reach of the general practitioner the means for conducting an efficient examination, including skin tests, as it must be the duty of paediatricians to see that men going into practice are taught the need for. and methods of examining child contacts. The attendance of general practitioners at post-graduate courses of instruction in this subject has already been mentioned.

7. Accommodation for treatment: Although this report is concerned with diagnosis, it must be pointed out that a widespread enquiry into child contacts would give rise to a large number of young children found to be suffering from a primary tuberculous infection and the care of these children would create a problem of its own. It must be recognised that for many children the outcome of their illness is decided in the first few months after infection, from which it is clear that early diagnosis can only lead to satisfactory results if followed by prompt and efficient treatment. Further, the majority of children needing treatment will be of the infant, toddler and preschool age group. For the majority of them treatment away from their homes would be required, and to nurse them through their illness in hospital wards would overload the cot capacity of the hospitals : nor is the environment of a hospital ward the best setting for their recovery. To nurse them in adult sanatoria is unwise owing to the risk of further infection: the nursing staff of these establishments is not particularly trained in the nursing of children and the accommodation that would be needed is not available. To meet this situation, convalescent homes in the country- preventoria - should be established and some of the existing convalescent homes possibly be given over for the care of these children. In addition to children showing a primary complex, those who are suffering from the various allergic manifestations (erythema nodosum, epituberculosis, pleurisy with effu- sion, phlyctenular conjunctivitis) should be eligible for these homes.

8. Summary: (a) In order to improve the present position with regard to the early diagnosis of intrathoracic tuberculosis in children, a much greater effort must be made to discover and examine children who have been exposed to cases of pulmonary tuberculosis of the adult type.

(b) To discover these children the machinery used by the tuberculosis officers should be employed.

(c) Special clinics should be set up for the examination of child contacts.

(d) Such clinics, whenever possible, should be set up at children's hospitals or children's departments of general hospitals and should be under the direction of a paediatrician.

(e) The investigation of children at these clinics should be carried out by the tuberculosis officer who should be affiliated to the medical staff of the hospital. It is considered that if co-operation on these lines could be established, some of the problems arising out of notification would find an automatic solution.

(f) Short courses of a post-graduate type, devoted to the subject of intrathoracic tuberculosis in children should be conducted by paediatricians.

(g) A corollary to the previous recommendations must be that convalescent homes in the country should be used for the care of children suffering from primary tuberculosis.

9. Recommendations to the executive committee of the British Paediatric Association: (a) This report be referred through the Chief Medical Officer of the Ministry of Health to the Minister, with a request for his assistance in putting the recommendations into practice.

(b) Copies of this report should be sent to the Association of Tuberculosis Officers, the Society of Medical Officers of Health, the British Post-Graduate Medical School, the Co-ordination Committee of the London Children's Hospitals, the Children's Hospitals and those General Hospitals having Children's Departments throughout the country.

(c) The executive committee should ask for a conference with a similar committee from the Association of Tuberculosis Officers in order to discuss the whole question of notification of tuberculosis in children. If at such a conference, agreement can be reached that difficulties exist and if practical solutions to these difficulties can be found, the combined committee should then approach the appropriate authority.

(d) In addition to a conference on notification, a conference embracing the other suggestions in this report will be required between the British Paediatric Association and the Association of Tuberculosis Officers and any other authorities concerned. If co-operation at such a conference can be obtained, the executive committee should then be prepared to approach the medical boards of hospitals containing a paediatric department to put this scheme before them.

(e) The executive committee should consider the advisability of publishing, at the appropriate time, as much of this report as they think fit in the medical press.

\title{
ARRANGEMENTS FOR NEWLY BORN BABIES IN MATERNITY HOSPITALS
}

By CHARles MCNEIL (Edinblrgh-ChairmaN), N. B. CAPON (Liverpool-Secretary), W. R. F. COLLIS (Dublis), S. GRAHAM (Glasgow) and A. MONCRIEFF (LoNdoN)

\section{(Report prefared by the British Paediatric Association, at the request of the Goodenough Committee)}

An ideal plan, assuming no restrictions, financial or otherwise : the chief aims being to safeguard the health of newly born infants, and to ensure that each baby on discharge from the hospital, with its mother, is breast fed, is in the care of a mother who has been instructed and is competent in the handling of her infant and that the mother is happy and anxious to have a family of reasonable size. 
1. General comments: (a) All the newly born babies (healthy, immature and sick) in a maternity hospital should be in the charge of a paediatrician who is experienced in this work, and who shall be a full member of the staff and advise on the general paediatric policy of the hospital. He should act in close co-operation with the obstetricians and with the public health medical officers of the district. The assistance required by the paediatrician will naturally depend upon local conditions, such as the size of the hospital : the minimum would be one assistant paediatrician (undergoing training in neonatal work), together with the services of one or more resident medical officers who must have had previous paediatric experience. One or more infant welfare clinics in the personal charge of paediatricians should be held in hospital for the benefit of mothers and babies, who should be instructed to report periodically after their discharge, if living in the vicinity of the hospital. A number of social workers and health visitors should serve on the staff of these clinics to visit the patients in their homes in order to ensure adequate supervision. Mothers and their babies from outlying districts would obviously attend the child welfare clinics nearest to their homes. Special attention at these clinics should be given to premature infants, and a liaison with the centre for prematures (see later) should be established.

(b) The above neonatal service should be part of the department or institute of paediatrics and should be fully used for research and for the teaching of postgraduates, undergraduates, nurses, health visitors and mothers.

(c) Even in an ideal plan it would be unwise, indeed impossible, to lay down hard and fast rules regarding some of the details of accommodation, etc., because local conditions must be taken into account. Thus, in some maternity hospitals, a much higher percentage of abnormal obstetrical cases occur than in other institutions, and in the former, it is to be expected that there will be a higher proportion of abnormal newborn babies. We should, however, record what we believe to be the basic needs, in so far as the infants are concerned: these are:-

(i) Every mother should be in a separate cubicle or room, large enough to accommodate her and her baby.

(ii) There must be a sufficient number of day and night nurses properly trained in the care of newly born infants and able to impart their knowledge to trainees. The health of the nurses must be supervised, and in the event of a nurse developing an infection such as a head cold, sore throat, diarrhoea or the like, she should not be allowed on duty until she is passed free of infection by the physician in charge.

(iii) Proper supervision of infant feeding, with special attention to breast feeding.

(iv) There should be established a special centre for the care of immature babies born both within the hospital and from the district. This is dealt with more fully under 5 .

(v) The formation of a breast milk ${ }^{*}$ pool ${ }^{*}$ or ${ }^{*}$ bank in the hospital for the in-patients and outpatients who are unable to receive breast milk from their mothers.

(vi) A properly equipped milk kitchen in which artificial feeds can be prepared and nurses taught the methods.

(vii) Adequate laundry arrangements for the washing and sterilizing of napkins. Suitable machinery should be installed.
2. Should babies be accommodated with their mothers or in special nurseries? We believe, as stated in (i) above. that each mother should be in a separate cubicle or room large enough to accommodate her and her child. For convenience in administration cubicles would be grouped into wards of 8 to 20 and the walls between adjacent cubicles would be glass in order that patients would not feel isolated. Babies would receive all necessary attention, e.g. bathing, clothing and feeding in the cubicle, and there would need to be in each cubicle adequate provision of equipment for the nursing care of the child for instance, bath, immersion and low-reading clinical thermometers, hot rails. trolleys, cupboards, weighing scales, closed receptacles for soiled napkins, etc. A gown and mask should be worn by every person entering a cubicle (doctors, nurses, students, visitors). Healthy infants should be in the care of nurses who are responsible also for the mothers, but the sister and staff nurses should be on the Sick Children's Nurses' Register, as well as holding the certificate of the C.M.B. Extra accommodation will be necessary for certain babies who, for various reasons may require to be removed from their mother's room, e.g. mother's illness, bad congenital abnormality in the infant, crying infants, and so forth. Accommodation for such infants would of course be of the cubicle type.

3 and 4 . What nursery accommodation should be provided for sick babies and what isolation facilities should be provided? Some paediatricians consider that maternity hospitals should be adequately staffed and equipped to enable them to deal with most of the 'medical diseases occurring during neonatal life : other paediatricians hold the view that all but the most trivial cases of neonatal illness should be removed to a children's hospital and that these institutions should have a number of rooms available for the reception of the mother as well as her child. If the first view is accepted it would naturally follow that maternity hospitals must provide accommodation for sick babies, and also have isolation facilities. We consider that an infant population of 75 would probably require 10 to 15 cots in a sick nursery or bay, and they should be isolated in cubicles with glass fronts on to a corridor and be air-conditioned. There should be a wash-hand basin in each cubicle : and arrangements for darkening a cubicle when necessary. Piped oxygen is an advantage. Sick infants should have a special staff (day and night) of nurses, trained as sick children s nurses, and the mask and gown system must be strictly used. Pupil midwives should receive an adequate training in these nurseries. A medical examination room adjacent to the sick bay would be an advantage.

5. Arrangements for prematures: It is necessary to have cubicles for premature infants, and the number will depend upon the type of obstetrical work done. In some maternity hospitals which deal with a relatively high proportion of abnormal cases, the prematures may be 10 per cent. to 20 per cent. of the total infants: in hospitals which accept a higher proportion of normal cases, the prematures will be 5 to 10 per cent. of the total infants. In the premature cubicles there must be special provision for conditioning the air (temperature and humidity), and some of the cots should be of special type. The staff must be adequate in number (day and night), the seniors being specially trained in the care of prematures, and not engaged upon other duties. Pupil midwives should receive instruction in the nursing of immature babies. Most of the points referred to in this statement are also dealt with, in some cases more fully, in the Report of the sub-Committee on Neonatal Mortality (Arch. Dis. Childh. 1943, 18, 62), which should be studied alongside this statement.

31 st Jan., 1943. 